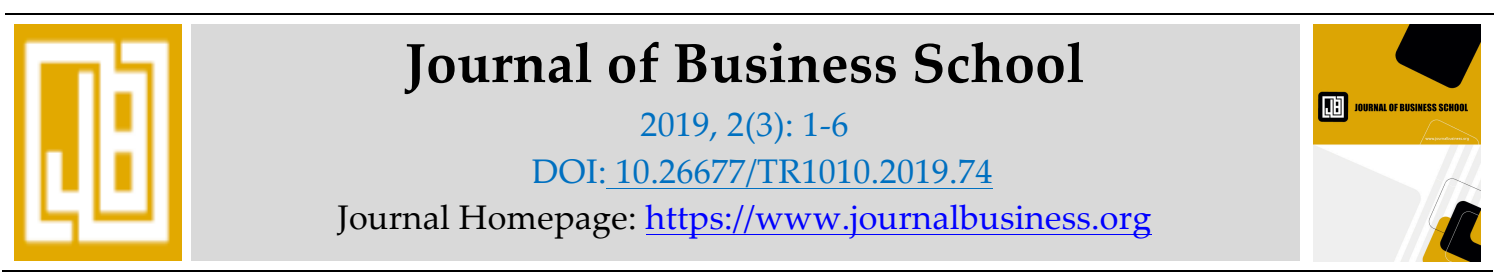

\title{
A Review on Open Source Solution for Cloud Computing
}

\section{Gajendra Sharma \& Amrita Rai}

Department of Computer Science \& Engineering, Kathmandu University, Dhulikhel. amrita.rai@student.ku.edu.np

\begin{abstract}
Cloud Computing is the latest evolution of internet based computing which assures to provide more flexibility, less expense, and more efficiency in IT services to end users. It is believed that governments, businesses and researchers all can benefit from the adoption of cloud computing services. The aim of this paper is to study four main open source cloud computing platforms available in the market. This paper also highlights their features and limitations which will definitely help service providers and enterprises for selecting best open source cloud computing solutions for their organization according to their needs.
\end{abstract}

Keywords: Open Source Solution, Cloud Computing

\section{INTRODUCTION}

\section{Background and Motivation}

In the recent times, "Cloud Computing" has been one of the most discussed terms in the world of Information Technology. The standard definition from the National Institute of Standards and Technology (NIST) is: "Cloud Computing is a model for enabling convenient, on-demand network access to a shared pool of configurable computing resources (e.g. networks, servers, storage, applications, and services) that can be rapidly provisioned and released with minimal management effort or service provider interaction". This model is composed of five essential features, three service models and four deployment models [1].

According to US NIST, five essential characteristics, three service models and four deployment models are as follows:

- Five characteristics: on-demand self-service, broad network access, resource pooling, rapid elasticity, and measured service.

- Three service models: Software as a Service (SaaS), Platform as a Service (PaaS), and Infrastructure as a Service (IaaS).

- Four deployment models: private clouds, community clouds, public clouds, and hybrid clouds. 
Cloud computing has been enabled by the developments in virtualization, distributed computing, utility computing, web and software services technologies. It is considered as the next natural step in the evolution of on-demand information technology services and products. Because of its various advantages like: lower cost, high scalability, fast processing, and convenience (i.e. anytime and anywhere), cloud computing is gaining its popularity in business and academic environment. [2]

While big companies such as Amazon, Google and Microsoft are offering public cloud infrastructures like Amazon Elastic Compute Cloud (EC2), Google AppEngine, Microsoft Azure, etc commercially in the market. Many other organizations are trying to set up "private clouds". Private clouds are internal to the organization providing more security, privacy, and better control on data usage and cost.

There are number of cloud platforms available in the market both commercial and open source softwares. Nowadays, an open source solutions for cloud computing are becoming more popular for organizations willing not to use commercially provided cloud. However, there are many open cloud platforms having their own characteristics and advantages making difficult for service providers and enterprises to choose between these platforms. And this difficulty in choosing appropriate cloud platform motivated me to do the study of open source cloud computing solutions available in the market.

\section{Problem Statement}

With the advancement in Information Technology, numbers of open source solutions are being developed with several features and purposes. However, for the successful utilization of cloud services it is very important to select appropriate cloud computing solutions according to one's needs and business requirements. There are various options for open source cloud computing platforms but the real problem lies in the selection of best open source cloud computing solutions which differ from individual to individual and organizations to organizations. Thus, this study is a step towards understanding several aspects of open source cloud computing platform which will help users to make a correct decision.

\section{Objective of Study}

The main objective of this study is to give a brief introduction of open source cloud computing platforms available in the market. The most popular open source platforms available in the market are: Eucalyptus, OpenStack, CloudStack and OpenNebula. The study also aims to highlight its features and limitaions which will definitely help users for selecting best open source cloud solutions according to their requirement.

\section{RESEARCH METHODOLOGY}

To fulfill the above objectives of study, this research is based upon the secondary data. The paper is written based on data collected from:

- Open source cloud computing websites

- Research articles

- Online journal papers

\section{LITERATURE REVIEW}

\section{Open Source Cloud Platforms}

Open source solutions provide flexibility to users not only to choose the product but also allow users to change source code for their own need. This ability of freedom and openness is 
encouraging more programmers to migrate towards the work on open source cloud packages as do not need to pay and look over proprietary issues. An open source cloud is growing and becoming more effective for the IT Industries and organizations who wanted to use the cloud facilities for hosting and other services. There are several open source cloud computing platforms available in the market. Among them the most popular are: Eucalyptus, OpenStack, CloudStack and OpenNebula. [3]

\section{Eucalyptus:}

EUCALYPTUS [4] is the full form for Elastic Utility Computing Architecture for Linking Your Program to Useful System, which is an open source private cloud software for building private or hybrid cloud resources for compute, network, and storage that are compatible with Amazon Web Service (AWS) APIs. It was developed by University of California-Santa Barbara for Cloud Computing to implement Infrastructure as a Service (IaaS). Eucalyptus provides an Elastic Compute Cloud (EC2) -compatible cloud Computing Platform and Simple Storage Service (S3)compatible Cloud Storage. Eucalyptus incorporates high-level components such as Cloud Controller (CLC), Cluster Controller (CC), Storage Controller (SC), and Node Controller (NC). The main benefit to use this open source software is for private clouds as it provides highly efficient scalability and organization agility. Main features [6] are:

- Images-Image is a group of software modules.

- Instances- If an image is using then it is called instance.

- IP addressing- Instances will get both public and private IP addresses when it is created.

- Security is provided by firewall.

- Networking- Three network modes: Managed mode, System mode and Static mode. In Managed mode, local network of instances are controlled where as physical LAN and cloud connection is established in System mode and in static mode DHCP server management and assigning IP addresses to the instances are possible.

\section{OpenStack:}

OpenStack [3,5] was announced in July 2010 and its initial contributors were NASA and Rackspace. It is one of the fastest growing free open source software available in the market. In the beginning, Rackspace contributed their "Cloud Files" platform (code) while NASA contributed their "Nebula" platform (code). OpenStack open source software is a collection of open source software project that any organization can use to setup and run their cloud compute and storage infrastructure. An OpenStack consist of several components- Compute (Nova), Object storage (Swift), Block storage (Cinder), Networking (Neutron), Dashboard (Horizon), Identity service (Keystone), Image service (Glance), Telemetry (Ceilometer), Orchestration (Heat), Database (Trove). Main properties of OpenStack are [6]:

- Component based architecture- One can easily add new components

- High availability

- Fault Tolerant

- Recoverable- Failures can be easily removed

- Open Standards

- API Compatibility 
- Nova follows shared nothing architecture and message passing for communication. Nova is a good interface with hypervisor.

- VM management and caching are the two functions of Nova.

\section{CloudStack:}

CloudStack [7] was initially developed by Cloud.com and purchased by Citrix then later on released into the Apache Incubator program. The first stable version of CloudStack was released in 2013 and this time governed by the Apache Software Foundation and supported by Citrix. CloudStack have commendable features such as:

- Storage independent compute

- New security features

- Smooth Deployment

- Scalability

- Multi Hypervisor support

- Detailed Documentation

- Interactive Web UI i.e. users can manage their cloud with an easy to use Web interface, command line tools, and/or a full-featured RESTful API.

- Access Control -Eucalyptus has an identity. This identity is grouped together for access control

\section{OpenNebula:}

OpenNebula [4] was first established as a research project back in 2005 by Ignacio M. Liorente and Ruben S. Montero. It is used by many enterprises as an open, flexible alternative to vCloud on their VMware-based data center. OpenNebula is primarily used as a virtualization tool to manage virtualized infrastructure in the data center, which is usually referred as private cloud and also supports hybrid cloud to combine local infrastructure with public cloud-based infrastructure, enabling highly scalable hosting environments. OpenNebula cloud infrastructure provides users with an elastic platform for fast delivery and scalability of services to meet the dynamic demand of service end-users. OpenNebula cloud computing toolkit is used by- hosting providers, telecom operators, IT services providers, supercomputing centers, research labs, and international research projects.

\section{Comparative Study of Cloud Solutions}

The following table [8] shows a comparative study of four main open source cloud computing platform based on their characteristics.

Table-1: Comparison of Open Cloud Platform Characteristics.

\begin{tabular}{|c|c|c|c|c|}
\hline Characteristics & Eucalyptus & OpenStack & CloudStack & OpenNebula \\
\hline License & Proprietary, & Apache license & Apache license & Apache license \\
\hline $\begin{array}{c}\text { Cloud } \\
\text { Implementation }\end{array}$ & $\begin{array}{c}\text { Private \& } \\
\text { Hybrid }\end{array}$ & $\begin{array}{c}\text { Private \& } \\
\text { Hybrid }\end{array}$ & $\begin{array}{c}\text { Public \& } \\
\text { Private }\end{array}$ & $\begin{array}{c}\text { Public, Private \& } \\
\text { Hybrid }\end{array}$ \\
\hline
\end{tabular}


Journal of Business School, vol.2, issue.3, pp.1-6

\begin{tabular}{|c|c|c|c|c|}
\hline Service Type & $\begin{array}{l}\text { Compute, } \\
\text { Storage }\end{array}$ & $\begin{array}{l}\text { Compute (Nova), } \\
\text { Storage (Swift) }\end{array}$ & $\begin{array}{l}\text { Service, Disk, } \\
\text { Network } \\
\text { Offerings and } \\
\text { Templates }\end{array}$ & $\begin{array}{l}\text { Compute, } \\
\text { Storage }\end{array}$ \\
\hline Compatibility & $\begin{array}{l}\text { Support } \\
\text { EC2,S3 }\end{array}$ & $\begin{array}{l}\text { Supports multiple } \\
\text { platforms }\end{array}$ & $\begin{array}{c}\text { Support } \\
\text { Amazon EC2 and } \\
\text { S3 APIs }\end{array}$ & $\begin{array}{l}\text { Open, } \\
\text { multiplatform }\end{array}$ \\
\hline Hypervisors & $\begin{array}{l}\text { Xen, KVM (VM } \\
\text { Ware in nonopen } \\
\text { source) }\end{array}$ & $\begin{array}{l}\text { Open } \\
\text { Virtualization } \\
\text { Format (OVF) }\end{array}$ & $\begin{array}{l}\text { VMware, KVM, } \\
\text { XenServer, Xen } \\
\text { Cloud Platform } \\
\text { (XCP) and Hyper-V }\end{array}$ & $\begin{array}{l}\text { Xen, KVM, } \\
\text { VMware }\end{array}$ \\
\hline $\begin{array}{l}\text { Programming } \\
\text { Framework }\end{array}$ & C, Java & Python & Java, Python & $\begin{array}{l}\text { C++, C, Ruby, } \\
\text { Java, Shell } \\
\text { script, lex, yacc }\end{array}$ \\
\hline $\begin{array}{l}\text { Disk Image } \\
\text { Options }\end{array}$ & $\begin{array}{l}\text { Options set by } \\
\text { admin }\end{array}$ & $\begin{array}{l}\text { Glance has } \\
\text { RESTful API }\end{array}$ & $\begin{array}{l}\text { Users can manage } \\
\text { their cloud with } \\
\text { Web interface, } \\
\text { command line } \\
\text { tools, RESTful } \\
\text { API }\end{array}$ & $\begin{array}{l}\text { In private cloud, } \\
\text { most libvirt } \\
\text { options left } \\
\text { open }\end{array}$ \\
\hline $\begin{array}{l}\text { Disk Image } \\
\text { Storage }\end{array}$ & $\begin{array}{l}\text { Walrus, which } \\
\text { Imitates Amazons } \\
\text { S3 }\end{array}$ & Nova & iSCSI or NFS & $\begin{array}{l}\text { A shared file } \\
\text { system, by } \\
\text { default NFS, or } \\
\text { SCP }\end{array}$ \\
\hline Characteristics & Eucalyptus & OpenStack & CloudStack & OpenNebula \\
\hline Unique Features & $\begin{array}{c}\text { User } \\
\text { management } \\
\text { web interface }\end{array}$ & $\begin{array}{c}\text { Unified } \\
\text { Authentication } \\
\text { System }\end{array}$ & $\begin{array}{l}\text { Clustered LVM, } \\
\text { NetScaler Support } \\
\& \\
\text { LDAP Integration }\end{array}$ & $\begin{array}{l}\text { VM migration } \\
\text { supported }\end{array}$ \\
\hline
\end{tabular}




\section{CONCLUSION}

Cloud Computing is the latest evolution of technology that has transformed the way hardware and software is now designed and delivered in the IT industry. Open source cloud platform provides an alternative to end-users for improved flexibility, scalability, portability and on demand services. The main advantage of open source solution is that they are customizable according to one's need and desire. This paper gave a brief introduction of four most popular and commonly used open source cloud solutions: Eucalyptus, OpenStack, CloudStack and OpenNebula. The paper also shows a comparative study which would help the users to understand the characteristics and limitations of above popular open source solutions making them able to choose better services according to their requirements.

Since cloud computing is an evolving technology and many features are being added day-to-day, here the comparison is based on the current features and technology available in these open source platform. However, there is need for incorporating many more features to improve the framework of available open source cloud solutions.

\section{REFERENCES}

[1] P. Mell and T. Grance, “The NIST Definition of Cloud Computing.” 07-Oct-2009.

[2] M. A. Vouk, "Cloud Computing - Issues, Research and Implementations," Journal of Computing and Information Technology, vol. 4, pp. 235-246, 2008.

[3] S. Sachdev and A. Mahajan, "Deployment of Private Cloud using Open Stack: An Open Source Cloud Computing Solution for Small and Mid-sized Organizations," International Journal of Advanced Research in Computer Science and Software Engineering, vol. 3, no. 10, pp. 292-304, Oct. 2013.

[4] S. Yadav, "Comparative Study on Open Source Software for Cloud Computing Platform: Eucalyptus, Openstack and Opennebula," Research Inventy: International Journal of Engineering And Science, vol. 3, no. 10, pp. 51-54, Oct. 2013

[5] O. SEFRAOUI, M. AISSAOUI, M. ELEULDJ, “OpenStack: Toward an Open-Source Solution for Cloud Computing", International Journal of Computer Applications, vol. 55, no. 03, Oct. 2012

[6] J. S., Manjaly, and J. S., "A COMPARATIVE STUDY ON OPEN SOURCE CLOUD COMPUTING FRAMEWORKS," International Journal Of Engineering And Computer Science, vol. 2, no. 6, pp. 2026-2029, 2013.

[7] "Apache Cloudstack," Apache Cloudstack. [Online]. Available:http://cloudstack.apache.org/. [Accessed: 20-Apr-2015].

[8] "Cloud computing comparison," Wikipedia, the free encyclopedia. 16-Apr-2015. 